2 Yadav R, Vidyarthi A. Electrocardiogram interpretation skills in psychiatry trainees. Psychiatrist 2013; 37: 94-7.

3 General Medical Council. Good Medical Practice. GMC, 2001

4 Craddock N, Antebi D, Attenburrow M-J, Bailey A, Carson A, Cowen P, et al. Wake-up call for British psychiatry. Br J Psychiatry 2008; 193: 6-9.

5 Joint Royal Colleges of Physicians Training Board. Specialty Training Curriculum for Core Medical Trainees. JRCPTB, 2009 amended 2012. (http://www.jrcptb.org.uk/trainingandcert/Documents/ 2009\%20CMT\%20framework\%20(revised\%20Aug\%202012).pdf).

Alison S. Lennox, CT1 in psychiatry, Oxford Health NHS Foundation Trust, Oxford, UK, email: alison.lennox@oxfordhealth.nhs.uk; Ben A. S. Wildblood, CT1 in medicine, North Bristol NHS Trust.

doi: $10.1192 / \mathrm{pb} .37 .7 .244 a$

\section{Why commissioners need to know about Section 136}

The article by Patrick Keown ${ }^{1}$ was a timely contribution to discussions currently taking place about the use of Section 136 between the Royal College of Psychiatrists, Home Office, Department of Health, Police, Health and Social Care Information Centre, and Care Quality Commission. A major and long-standing problem in understanding the trends in the use of this power has been the failure to collect complete information on the use of Section 136, as the author points out, referring to data collected in 2005-2006. We would like to draw attention to more recent data collected in 2011-2012: these show a dramatic increase in rates of detention under Section $136-43 \%$ in 6 years, from 16500 to 23569 . $^{2}$ Although the number taken to custody suites has fallen from 11500 (2005-2006) to 8667 (2011-2012), this figure still far exceeds the anticipated number if custody suites were used in 'exceptional circumstances only', as described in the Mental Health Act 1983 Code of Practice, $^{3}$ and reiterated in the Royal College of Psychiatrists' guidance. ${ }^{4}$

In 2012, the Association of Chief Police Officers (ACPO) collected information on the use of Section 136 in all 43 police areas and discovered that $37 \%$ of those detained under Section 136 continue to go to a custody suite, although this varies between force areas. Despite approximately $£ 130$ million of capital funding having been made available for Section 136 suites 7 years ago, there are several police forces in England that still do not have access to hospital places of safety 24 hours a day and/or when demand exceeds capacity. This unacceptable variability in provision is clearly a commissioning issue and in March this year the College produced guidance for local commissioners in order to help identify shortfalls in local service provision. ${ }^{4}$

The multi-agency Mental Health Act group chaired by the College is collecting more detailed information on local services and would be delighted to receive completed surveys (www.rcpsych.ac.uk/pdf/PS02_2013_survey.pdf) from members to inform further discussions.

1 Keown P. Place of safety orders in England: changes in use and outcome, 1984/5 to 2010/11. Psychiatrist 2013; 37: 89-93.

2 Health and Social Care Information Centre. Inpatients Formally Detained in Hospitals Under the Mental Health Act 1983 and Patients Subject to Supervised Community Treatment - England, 2011-2012, Annual Figures. HSCIC, 2012 (http://www.hscic.gov.uk/catalogue/PUB08085).

3 Department of Health. Mental Health Act 1983 Code of Practice. TSO (The Stationery Office), 2008.
4 Royal College of Psychiatrists. Guidance for Commissioners: Service Provision for Section 136 of the Mental Health Act 1983 (Position Statement PS2/2013). Royal College of Psychiatrists, 2013.

Julie S. Chalmers, Consultant Psychiatrist, The Elms Centre, Banbury, and Honorary Senior Clinical Lecturer, University of Oxford, email: Julie.Chalmers@oxfordhealth.nhs.uk; Michele Hampson, Specialist Advisor, Mental Health Law, Royal College of Psychiatrists, London, UK.

doi: $10.1192 / p b .37 .7 .245$

\section{Getting it right for people with dementia}

Steve llife's editorial is perceptive, diplomatic and hopefully not too late. ${ }^{1}$ As he makes clear, dementia is not, for most people, a stand-alone condition. Once established it remains significant in determining quality of life and need for help and support right to the end of an individual's life. Every journey with dementia is unique and will not be constrained by a predictive pathway or tidied into convenient once-and-for-all time phases.

Our model of specialist involvement in primary care in Gnosall Memory Service, which is dismissed as third choice by psychiatrists in the South West, has the advantage of proven sustainability over nearly 7 years. The arrangements bring the specialist expertise of psychiatry into the practice and the practice retains the clinical responsibility for patients. Many are elderly and carry a number of illnesses for which they attend the practice: a memory problem is simply one of a spectrum of challenges, and attendance at a practice clinic is an acceptable addition to the patient's routine. Patients are seen as people with full lives with important social and family involvement. An integrated and collaborative approach achieves rapid access to assessment, diagnosis and care planning, with high satisfaction by all parties and reduced usage of other components of the mental health and general hospital economies. ${ }^{2-4}$

The Gnosall experiment was not intended to remain an isolated enterprise: several visiting teams have taken the essentials of the model and begun similar services elsewhere. We have described a three-tier model which foresees the integration of the work in primary care within a reorganised district memory service as a component of the old age psychiatry service. $^{5}$

We are currently working with commissioners, South Staffordshire and Shropshire Healthcare NHS Foundation Trust, and a federation of over 30 primary care outlets that cover 360000 patients, with a view to implementing this vision over a wider area. This is not a pathway to loss of special skills, independence or status, but the logical way to deliver a sensitive, comprehensive and affordable service for every individual and every family with dementia in the UK in the 21st century.

Declaration of interest

All authors contribute to the work of the Gnosall Memory Service.

1 lliffe S. Commissioning services for people with dementia: how to get it right. Psychiatrist 2013; 37: 121-3.

2 Greening L, Greaves I, Greaves N, Jolley D. Positive thinking on dementia in primary care: Gnosall Memory Clinic. Community Pract 2009; 82: $20-3$.

3 Greaves I, Jolley D. National Dementia Strategy: well intentioned but how well founded and how well directed? Br J Gen Pract 2010; 60 193-8. 